\title{
Applications of Staffing, Scheduling, and Budgeting Methodologies to Hospital Ancillary Units
}

\author{
Myeng-Ki Kim and Walton M. Hancock
}

\begin{abstract}
A computer-aided methodology for integrating the budgeting, staffing, and labor productivity systems of Ancillary Services using Respiratory Therapy as an example is presented. The data needed, staffing computations and schedules, and productivity analysis are presented and discussed. A summary of the predicted savings and other benefits for the application hospital are presented with comparisons to present productivity systems.
\end{abstract}

\section{INTRODUCTION}

With hospitals placing increased focus on their internal costs, a need exists for computer aided methodologies for ancillary services that will integrate the budgeting, staffing, and productivity reporting systems. Second, there is a major need to help the management engineers provide guidance to the management about what level of productivity should be attainable, and third, there is a need to provide sufficient staffing on every shift so that the work gets done, thus meeting quality and minimum length of stay requirements. This paper addresses the specific need for Ancillary Departments to: day.

1. Collect data on the procedures requested of the Ancillary Services by shift and by

2. Determine the minimum cost staffing to meet the needs (get all of the work done) by shift and by day.

3. Adjust for the varying quality of labor standards.

4. Provide daily staffing schedules for full- and part-time employees, by shift and by day, taking into account the work demand, vacations, holidays, and number of weekend requirements.

This paper presents the experience of the authors in applying these methodologies,

From the Industrial \& Operations Engineering Department, The University of Michigan, Ann Arbor, Michigan 48109-2110. 
which are reported in detail elsewhere, ${ }^{1-3}$ to Physical Therapy, Respiratory Therapy, the Laboratories and the Pharmacy of a 600 bed tertiary care hospital. The hospital was judged by the authors to have developed computer aided cost control procedures that were much more effective than the majority of hospitals. Toward this end, they had a labor productivity system where the standards were established by professionals, a labor reporting and productivity system, and a budgeting system that was partially integrated with the labor productivity system. As we shall see, changes would have to be made to the computer systems, personnel scheduling, and budgeting process and labor productivity systems, but the cost savings are well worth the effort.

\section{METHODOLOGY DESCRIPTION}

The following is an outline of the methodology procedure used.

1. The procedures by shift by inpatient and outpatients by service are multiplied by the labor standards and then summed. This produces the total earned hours by shift for inpatients and outpatients for each day.

2. The staff hours actually worked by shift by service are obtained. Vacation, sick leave, and hours worked off the unit are excluded from the staff hours actually worked.

3. The percentage productivity for each day by shift by service is computed and graphed, where

$$
\% \text { Productivity }=\frac{\text { Earned Hours }}{\text { Staff Hours Worked }} \times 100
$$

4. The near maximum productivity is determined by examination of the graph produced in 3. above. Near maximum is that productivity that has been obtained at least two or three times during the data collection interval. The objective here is to determine the capability (percentage productivity) of the work force under high demand (workload) conditions using labor standards in use at the particular institution. This procedure adjusts for the varying quality work standards.

5. The following equations are then used to determine the staff hours and FTEs needed on day $D$, shift $S$.

$$
\begin{aligned}
\mathrm{SH}_{\mathrm{DSC}} & =\frac{\mathrm{MAX}_{\mathrm{DSC}}(100)\left(\mathrm{H}_{\mathrm{SC}}\right)}{\left(\mathrm{H}_{\mathrm{SC}}+\mathrm{OV}_{\mathrm{SC}}\right) \%_{\mathrm{C}}} \\
\mathrm{FTE}_{\mathrm{DSC}} & =\frac{\mathrm{SH}_{\mathrm{DSC}}}{\mathrm{H}_{\mathrm{SC}}},
\end{aligned}
$$

where

$\mathrm{SH}_{\mathrm{DSC}}=$ The staff hours needed for day $\mathrm{D}$, shift $\mathrm{S}$, clinical service $\mathrm{C}$ for the future period

MAX ${ }_{\text {DSC }}=$ The maximum earned hours for day D, shift $S$, clinical service $C$ in the database

$\mathrm{H}_{\mathrm{SC}} \quad=$ The number of available working hours in the shift excluding breaks 
$\mathrm{OV}_{\mathrm{SC}}=$ The maximum amount of overtime permitted per shift per employee, by shift, clinical service $\mathrm{C}$

$\%_{\mathrm{C}} \quad=$ The near maximum $\%$ productivity of the workforce on a daily basis, clinical service $\mathrm{C}$.

6. The following are the equations to determine percentage productivity and direct staffing cost per week.

$$
\text { \% Productivity }=\frac{\frac{\Sigma E H_{D S C}}{W_{D S C}}}{\sum_{D=1}^{7} S_{D S C}} \times 100
$$

where

$\Sigma E H=$ is the total earned hours in the demand data on day $D$, shift $S$, and clinical service $\mathrm{C}$

$\mathrm{W}=$ is the number of weeks of demand data on day $\mathrm{D}$, shift $\mathrm{S}$, and clinical

Direct Staffing Cost $/ \mathrm{wk}=\sum_{\mathrm{D}=1}^{7} \mathrm{SH}_{\mathrm{DSC}}\left(\mathrm{H}_{\mathrm{C}}+\mathrm{HB}_{\mathrm{C}}\right)+1.5\left(\sum_{\mathrm{D}=1}^{7} \mathrm{OVH}_{\mathrm{DSC}}\right)\left(\mathrm{H}_{\mathrm{C}}\right)$

Where

$\mathrm{H}_{\mathrm{C}} \quad=$ Straight Time Hourly costs

$\mathrm{HB}_{\mathrm{C}} \quad=$ Hourly fringe benefits

$\mathrm{OVH}_{\mathrm{DSC}}=$ Average overtime hours/day as computed for each day of the week of the demand data using the values of $\mathrm{SH}_{\mathrm{DSC}}$ as the staffing level.

7. Work schedule for full time employees

A. When no one is on vacation

(1) Determine the days off policies of the hospital

(2) Use computer-based heuristic to determine the number of full-time people required subject to the constraint that part-time staff will be required will be in the interval of 0 to 0.99 FTE on at least one day of the week [2]

B. When one (for example) employee is on vacation

(1) Do A. above.

(2) Delete the employee on vacation from the work schedule.

(3) Compute for each day

Part-time staff required $=$ Total Required Full-time staff-employees scheduled to work.

8. To compute vacation and holiday and compensatory budget

A. For each employee assigned to unit, compute the number of days of vacation privilege of sum. Multiply by $\left(\mathrm{H}_{\mathrm{C}}+\left(\mathrm{HB}_{\mathrm{C}}\right)\right)$ 
9. To determine vacation, holiday and compensatory staffing

A. For the staffing period being scheduled, determine on a day of the week basis the number of full-time people that will be off.

B. Recompute the part-time staff required using the same algorithm as 7.B.3.

\section{DATA COLLECTION}

The procedure followed was to obtain a computer database of the daily records for each ancillary service as follows.

1. The procedures done by shift by inpatient and outpatient source for each department.

2. The staff hours worked by shift for each department.

3. The labor standards for each procedure.

Several problems occurred in collecting the above data that appear to be typical of many hospitals. These were:

1. The procedures that were done were accumulated by the computer system for two week intervals with the daily data being erased after a short period of time. Thus, some of the basic demand data necessary to schedule the staff on a daily basis was being discarded. This was changed so that the daily data was downloaded onto a separate tape for project use. Getting this tape from the computer service company took considerable time and effort because of the extensive use by the service company and hospital of "canned" software. Since we were interested in shift data, the analysis of Pharmacy and Physical Therapy is not reported here because we could only get procedure (demand) data for 24-hour periods, which is insufficient for shift staffing purposes unless only a one shift operation is involved.

2. The staff hours worked by shift were collected on cards, totaled, and the total entered into the computer every two weeks. For purposes of this project, the daily staff hours by shift were entered into a microcomputer with the expectation that the hospital computer system would be modified to accept daily data in the future and provide on a database the staff hours worked by shift.

\section{AN EXAMPLE OF THE USE OF METHODOLOGIES}

For purposes of illustration, the following section contains a description of the application of the staffing methodologies to Shift 3 of Respiratory Therapy followed by a summary of the results of application to all units.

\section{Demand Data}

Respiratory Therapy was a three shift, 7-day per week operation. Thus, it was decided that the use of overtime, in order to meet the variation in demand, would not be practical because the overtime staff would interfere with the activities of the regular staff. Examination of a sample of the demand data (Table 1) indicated high variation between days of the week and within days. Thus, the methodology indicated that a minimum cost 
Table 1. Sample Demand Data in Earned Hours for Respiratory Therapy, Third Shift

\begin{tabular}{ccccccccc}
\hline $\begin{array}{c}\text { Week } \\
\text { no. }\end{array}$ & Sun. & Mon. & Tues. & Wed. & Thur. & Fri. & Sat. & Total \\
\hline 1 & 64 & 50 & 36 & 49 & 27 & 19 & 89 & 334 \\
2 & 67 & 65 & 61 & 59 & 57 & 11 & 49 & 369 \\
3 & 52 & 40 & 25 & 20 & 49 & 51 & 37 & 274 \\
4 & 34 & 47 & 15 & 72 & 65 & 41 & 51 & 325 \\
5 & 60 & 60 & 61 & 60 & 58 & 53 & 73 & 425 \\
6 & 72 & 121 & 76 & 26 & 58 & 39 & 82 & 474 \\
7 & 73 & 108 & 70 & 35 & 78 & 87 & 41 & 492 \\
8 & 59 & 102 & 107 & 96 & 111 & 48 & 44 & 567 \\
Total & & & & & & & & 3260 \\
\hline
\end{tabular}

solution is to staff differently on each day of the week. The earned hours of Table 1 are obtained as described under Methodology Description, No. 1.

\section{Staffing Computations}

Table 2 is a partial output of the methodology which gives the required staffing by day of the week for the future period. The staffing hours were determined using Step 5 under Methodology Description with the near maximum productivity established at $180 \%$ by examination of the actual productivity data graph of Fig. 1 and selecting a near maximum figure that has been achieved several times.

Using the data of Table 1 and Equation (1), example calculations to obtain the results of Table 2 are:

$$
\begin{aligned}
\mathrm{SH}_{\mathrm{DSC}} & =\frac{73(100)(8)}{(8+0) 180}=40.6 \text { Hours (For Sunday) } \\
\mathrm{FTE}_{\mathrm{DSC}} & =\frac{40.6}{8}=5.1 \text { (For Sunday) }
\end{aligned}
$$

The Average \% Productivity $=\frac{\frac{3260}{8}}{379.9} \times 100=107.3 \%$

The Direct Staffing Cost/wk $=379.9(\$ 16.00+\$ 4.00)+(0)=\$ 7598.00$

Table 2. Required Staffing by Day of the Week for the Future Period

\begin{tabular}{lcccccccc}
\hline & Sun. & Mon. & Tues. & Wed. & Thur. & Fri. & Sat. & Sum \\
\hline Staffing & & & & & & & \\
Hrs. & 40.6 & 67.2 & 59.4 & 53.3 & 61.7 & 48.3 & 49.4 & 379.9 \\
Overtime hr $_{\text {FTEs }^{a}}$ & 0 & 0 & 0 & 0 & 0 & 0 & 0 & 0 \\
& 5.1 & 8.4 & 7.4 & 6.7 & 7.7 & 6.0 & 6.2 & 47.5 \\
& \multicolumn{7}{c}{ Average \% productivity } & $=107.3 \%$ \\
& Direct staffing cost per week $=\$ 7598.00$ \\
\hline
\end{tabular}

${ }^{a}$ Full-time equivalents. 


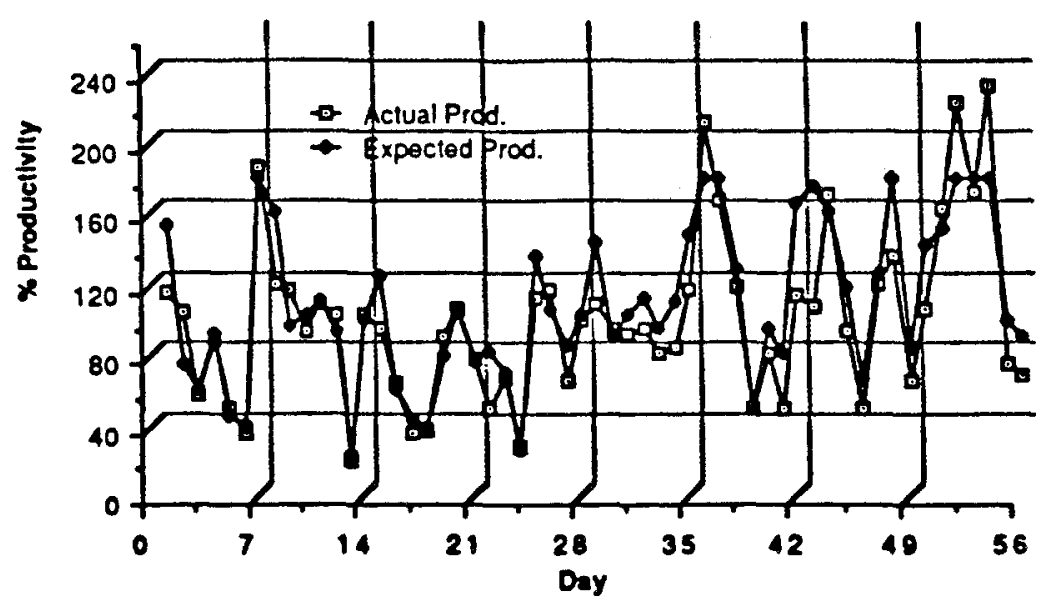

Figure 1. Comparison of percentage productivity for respiratory therapy, Shift 3.

Where the average straight time labor cost is assumed to be $\$ 16.00 / \mathrm{Hr}$. with fringe benefits of $\$ 4.00 / \mathrm{Hr}$. and overtime costs of (0) because no overtime is to be used.

The percentage productivity of $107.3 \%$ is higher than figures frequently assumed in many hospitals of $85 \%$ to $100 \%$. Please note that percentage productivity is determined by what the work force has demonstrated they are capable of doing using the labor standards in effect and not by an arbitrary figure as is common practice.

The daily staff $\left(\mathrm{SH}_{\mathrm{DSC}}\right)$ is determined by using the maximum earned hours for each day (Example: 73 hours for Sunday). This is done because of the need to get all of the work done each shift. Work which is carried over may cause the length of stay to increase. This is not cost effective and may have a negative impact on the quality of care and repeat orders.

The weekly budget $(\$ 7598.00)$ assumes that the staffing will be done according to the FTE daily schedule and assuming straight time $(\$ 16.00 / \mathrm{Hr})$, fringe benefits $(\$ 4.00 / \mathrm{Hr})$ and overtime $(\$ 24.00 / \mathrm{Hr})$ are compensated according to hospital policy. Monthly and annual budgets may be obtained by extending the weekly figures and adding to them the costs of the necessary administrative staff and the replacement costs of personnel on vacation, sick leave, and compensation days.

The hours and FTEs of Table 2 are not rounded because of the errors it causes and because part-time staff within a shift can frequently be used by having a person work a part shift or a person working in more than one department during the shift.

\section{Graphical Displays of Productivity}

Figure 1 is a plot of $\%$ Productivity before the application of the methodology (Actual Prod.), and with the proposed staffing levels (Expected Prod.) using the methodology.

Using the $180 \%$ near maximum figure, the Expected Productivity curve of Fig. $1^{*}$

* Figures and tables in this paper are reproduced from Reference 2 with permission. 
was produced where the average productivity is $109.8 \%$ as compared to $99 \%$ for actual productivity.

\section{STAFFING SCHEDULES}

Table 2 gives the information on how much staff should be available to work on each day of the week to accomplish the work to be done using Equation (1). To this required staff has to be added part-time staff when the full-time staff is on vacation or when they are taking a compensatory day, due to working holidays. The holiday and compensatory day scheduling requires data specifying the amount of vacation each employee is entitled to and the number of holidays during the year. Using this information and the required staff data of Table 2, Fig. 2 is produced. This table provides the data necessary to tell each employee (Emp. No.) when they should work, when no member of the full-time staff is on vacation, and when one full-time staff is on vacation. In this particular situation, Schedule A would be used for 20 weeks and Schedule B for 32 weeks during the calendar

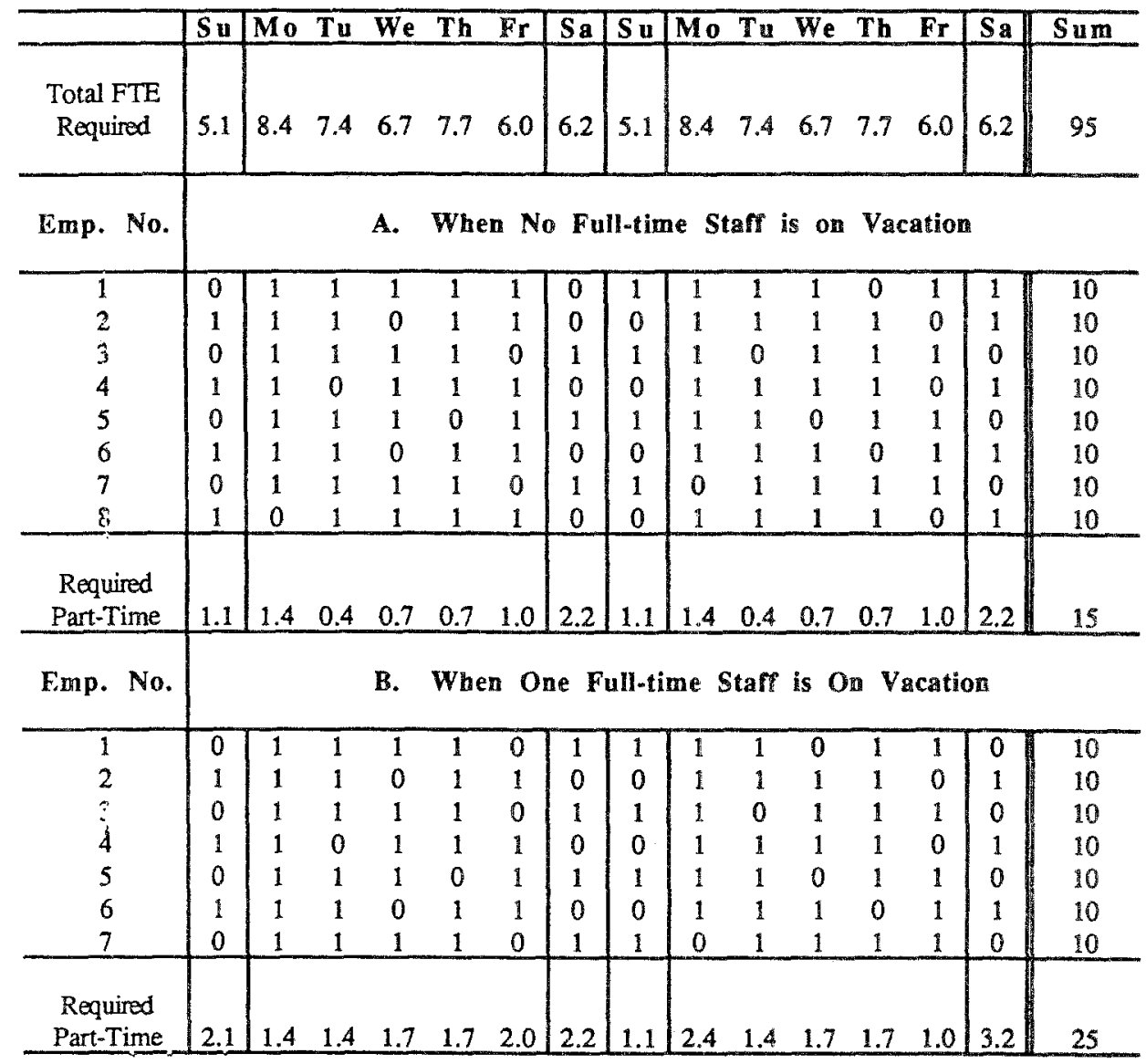

Figure 2. Scheduling and vacations and holidays assignment for respiratory therapy, Shift 3. 
year. The number of weeks of Schedule B is dependent on the total amount of vacation the full-time staff are entitled to, which in this case is one FTE for 32 weeks.

The schedule is one of many that can be developed. This particular example is developed under the assumption that each employee will work 10 days in a two week period with every other weekend off and that no more than one full-time staff person is on vacation at any one time. The schedule is for a two week period because this is the minimum number of weeks necessary to develop a schedule where the full-time staff have every other weekend off.

Employees are identified by "Employee No." Each employee is given a basic two week schedule where a " 1 " is the days the employee should work and a " 0 " is his/her days off. The part-time staff is broken into two categories: required part-time which can be scheduled in advance and residual part-time which is necessary if one of the full-time staff wants to take a compensatory day off on the particular day.

The department heads and the Finance Department were very pleased with this information because it gave the department head detailed information as to when to schedule people so that the expected productivity of $109.8 \%$ could be achieved. The department heads' job is clarified because if he/she schedules according to the information supplied, variation in percentage productivity will be due to changes in demand which are not the department heads' responsibility. If the staffing numbers are incorrect, then it is the responsibility of the schedule developer, not the department head.

\section{PROJECTED SAVINGS}

Table 3 is a summary of the results of examining the three shifts of Respiratory Therapy and four laboratories that are opening on a one shift basis. Specific attention should be paid to the following:

1. Column 1 is the present actual staff working, including holiday and compensatory time in FTEs. Column 3 is the staff that is recommended using the methodology. Column 4 is the difference in staff between the present staff and the proposed methodology. The difference is 33.1 FTEs per week.

2. The 33.1 FTEs are not solely due to the methodology. Column 5 is the present productivity that is being achieved. Using a frequent criteria that $85 \%$ productivity is reasonable to achieve, all except two of the departments are overstaffed. Using the $85 \%$ productivity criteria, the results of Table 4 are obtained. Thus, of the total of 33.1 FTEs potential savings, approximately 12.9 FTEs could be saved if the present productivity system were properly used and 20.2 FTEs are due to the proposed system. The authors asked why the present system did not provide better results, and the administrators responded by saying that the present productivity system, which is based on 2-week reporting periods, did not provide them with enough specific information about what actions to take with regard to staffing and replacements and vacation schedules to attain the expected productivity figures without incurring understaffing.

3. Column 2, Table 3 , contains the "near maximum productivity" which is the maximum capability that the workforce can achieve using the approach described in the respiratory therapy example. Please note the following:

A. The capabilities differ substantially between departments with a range of 


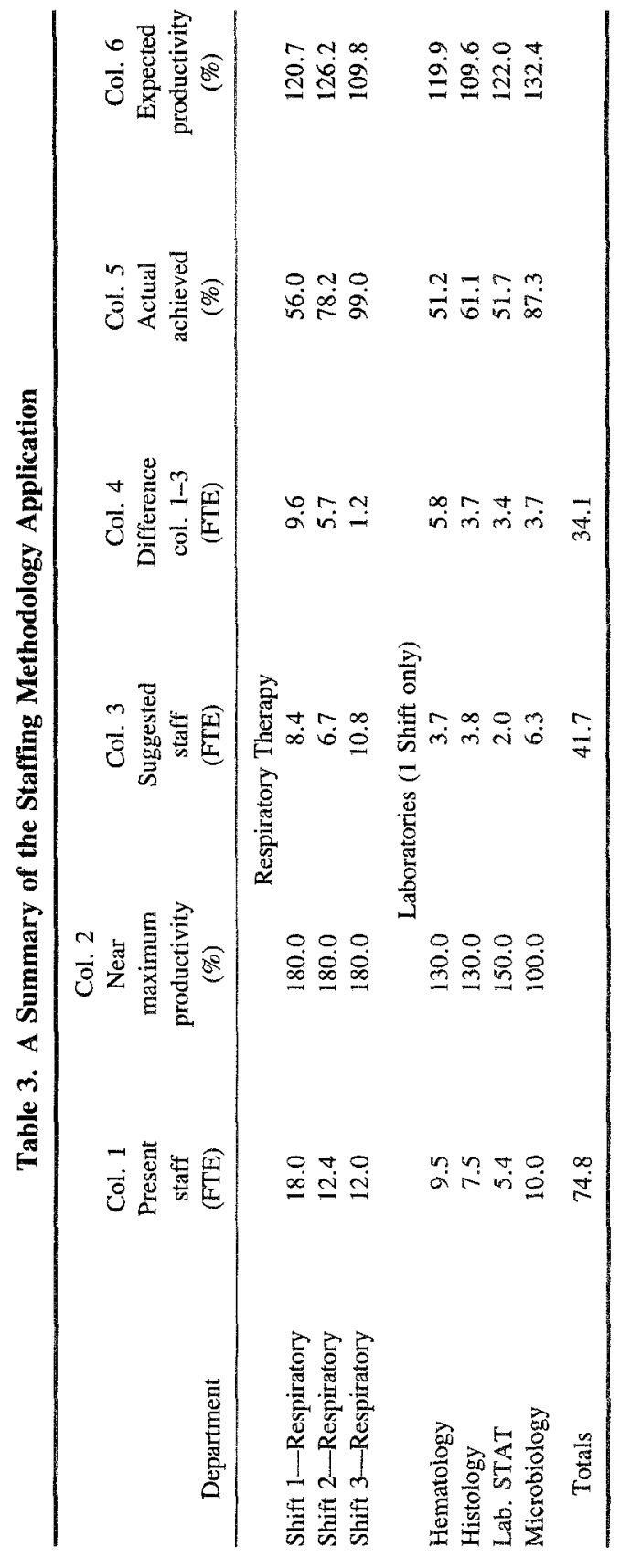


Table 4. The Staff Savings Due to the Methodology

\begin{tabular}{lccc}
\hline \multicolumn{1}{c}{ Department } & $\begin{array}{c}\text { Column 1 } \\
85 \% \text { Staff } \\
\text { productivity } \\
\text { (FTE) }\end{array}$ & $\begin{array}{c}\text { Column 3 } \\
\text { Suggested } \\
\text { staff } \\
\text { (FTE) }\end{array}$ & $\begin{array}{c}\text { Projected } \\
\text { savings } \\
\text { (FTE) }\end{array}$ \\
\hline Respiratory, Shift 1 & 11.8 & 8.4 & 4.0 \\
Respiratory, Shift 2 & 11.4 & 6.7 & 4.7 \\
Respiratory, Shift 3 & 14.0 & 10.8 & 3.2 \\
Hematology & 5.7 & 3.7 & 2.0 \\
Histology & 5.4 & 3.8 & 1.6 \\
Laboratory Stat. & 3.3 & 2.0 & 1.3 \\
Microbiology & 10.3 & 6.3 & 4.0 \\
\multicolumn{1}{c}{ Totals (FTEs) } & 61.9 & 41.7 & 20.2 \\
\hline
\end{tabular}

$130 \%$ to $180 \%$. This difference is probably due to the varying quality of labor standards, to situations where the work is being done without following the protocols specified in the labor standards and to the ratio of inexperienced to experienced employees.

B. The adjusted capability for Hematology of $130 \%$ had to be established using data in the literature concerning the maximum average capability of people in the workforce where standards are carefully established [2]. This was done because the department was so overstaffed that the variation in demand provided daily productivities that did not exceed $100 \%$. It is difficult to establish the figures of Column 2 with departments exhibiting very high overstaffing. This situation will change by periodic reanalysis of the adjusted capability using $130 \%$ initially.

4. The maximum productivity figures of Column 2, Table 3, appeared high to administrators and to the authors. Presentations of the methodology rationale to the department heads were helped considerably by several factors. For example, the graphs like Table 2 helped them understand that the staff had performed above the near maximum productivity level on several occasions. Also, the graphs helped them understand the need to staff differently each day and to base the expected productivity, not on an arbitrary figure (like $85 \%$ ), but on a methodology that determines what is possible based on maximum percentage performance and on the extent of variation in demand.

\section{IMPLEMENTATION STRATEGY}

Successful continued use and development of integrated budget, staffing and productivity systems requires the hospital's computer system to collect on a daily-shift basis the following data:

1. The procedures done and the time they were either started or finished.

2. The staff hours worked by straight time and overtime by name or employee ID number.

3. The amount of vacation each employee will take.

4. The salary rates of the employees. 
It is desirable to produce the output described in this paper by downloading the files to a microcomputer because it is important to obtain graphical output of the demand hours in order to detect input errors and trends in the data. Since immediate past demand data are used to determine staff levels for the future, data partitioning to remove demands that are not likely to repeat is desirable before proceeding with the methodology. Also, modification of the partitioned data may be desirable to meet projected increases or decreases in future demand.

The greatest difficulty to getting the system fully implemented and useable is to get the data indicated above on computer files so that the methodology can be used easily at periodic intervals. Once this is accomplished, the direct labor budgeting, staffing schedules, and productivity systems can be integrated with relative ease and with the potential savings indicated in this paper.

\section{REFERENCES}

1. Hancock, W.M., and Chan, T.J., Productivity and Staffing of Hospital Units with Uncertainty in the Demand for Service. IIE Transactions 20(4):346-353, 1988.

2. Kim, Myeng-Ki, Staffing and Scheduling Methodologies for Hospital Ancillary Units, Ph.D. Dissertation, University of Michigan, May, 1988.

3. Hancock, W.M., Pollock, S.M., and Kim, Myeng-Ki, A model to determine staff levels, cost, and productivity of hospital units. J. Med. Sys. 11(5):319, 1987. 